\title{
Exercise as a substitute for traditional airway clearance in cystic fibrosis: a systematic review
}

\author{
Nathan Ward, ${ }^{1,2}$ Scott Morrow, ${ }^{1}$ Kathy Stiller, ${ }^{3}$ Anne E Holland ${ }^{2,4,5}$
}

${ }^{1}$ Physiotherapy and Cystic

Fibrosis Services, Royal Adelaide Hospital, Adelaide, South

Australia, Australia

2Department of Physiotherapy,

Podiatry, and Prosthetics and

Orthotics, La Trobe University,

Melbourne, Victoria, Australia

${ }^{3}$ Allied Health, Central Adelaide Local Health Network, Adelaide,

South Australia, Australia

${ }^{4}$ Physiotherapy, Alfred Health,

Melbourne, Victoria, Australia

${ }^{5}$ Allergy, Immunology and

Respiratory Medicine, Monash

University, Clayton, Victoria,

Australia

\section{Correspondence to}

Nathan Ward, Royal Adelaide

Hospital, Adelaide, SA 5000,

Australia;

nathan.ward2@sa.gov.au

Received 20 July 2020

Revised 29 October 2020

Accepted 1 December 2020

Published Online First

22 December 2020

\section{ABSTRACT \\ Background Exercise and traditional airway clearance techniques (ACTs) are both routinely recommended for people with cystic fibrosis (CF), with some people using exercise as a substitute for traditional ACTs. The effectiveness of this is unclear. We systematically reviewed the evidence for using exercise as a substitute for traditional ACTs in people with CF.}

Methods A systematic database and literature search were undertaken of studies comparing exercise to rest or traditional ACTs. Primary outcomes were respiratory function, respiratory exacerbations and healthrelated quality of life. Secondary outcomes included mucociliary clearance (MCC), sputum weight and ease of expectoration. Data are mean difference $(95 \% \mathrm{Cl})$.

Results A total of 12 studies (15 reports) were included, all of short duration (single session to 2 weeks). In crossover trials, exercise did not improve forced expiratory volume in one second in comparison to rest, but peak expiratory flow was increased during treadmill exercise (mean difference (MD) range 1.00-1.16 L/s) and cycle ergometry (1.19 (0.96 to 1.42$) \mathrm{L} / \mathrm{s})$. Treadmill exercise improved MCC (2.6 (1.6 to 3.6)\%) and ease of expectoration (MD range $1.3-1.8 \mathrm{~cm}$ ) compared with rest. No consistent differences in respiratory function were evident when exercise was compared with traditional ACTs (four crossover studies). There was no significant difference in MCC or sputum weight in studies where forced expirations were included in the exercise intervention.

Conclusions Exercise improves ease of expectoration and sputum clearance compared with rest. Exercise, incorporating forced expirations, may have similar effects to traditional ACTs over the short term. There are no data comparing exercise to traditional ACTs over the longer term.

PROSPERO registration number CRD42018102780.

\section{INTRODUCTION}

Historically, people with cystic fibrosis (CF) have been prescribed a daily routine of airway clearance techniques (ACTs) with the aim of reducing symptoms and slowing decline in respiratory function. Traditional ACTs included postural drainage (PD), percussion and vibrations (P\&V) but have evolved to include breathing techniques (eg, active cycle of breathing technique (ACBT), autogenic drainage (AD)) and device-based ACTs such as positive expiratory pressure (PEP) and oscillating PEP. It is recommended that people with $\mathrm{CF}$ undertake regular exercise, to improve aerobic fitness and muscle strength, in addition to performing ACTs. ${ }^{1-4}$

\section{Key messages}

What is the key question?

- While people with cystic fibrosis commonly report using exercise as a substitute for traditional airway clearance techniques, is there evidence to support this practice?

What is the bottom line?

- Short-term studies indicate exercise improves mucociliary clearance compared with resting. Exercise may be as effective as traditional airway clearance techniques however the evidence is limited by short-term studies and conflicting results. There is no medium or longterm evidence to guide clinical practice.

Why read on?

- This review systematically evaluates the evidence for using exercise as a substitute to traditional airway clearance techniques in people with cystic fibrosis and provides insight into clinical practice and future studies in this area.

However, a recent survey of Australian adults with CF found that $43 \%$ of the participants agreed or strongly agreed that exercise could be used as a substitute for traditional ACTs, while analysis of the UK CF data registry found that $16 \%$ of patients reported that exercise was their primary method of airway clearance. ${ }^{56}$

The physiological rationale for using exercise as a substitute for traditional ACTs includes that moderate intensity exercise reduces epithelial sodium conductance and nasal potential difference in people with $\mathrm{CF}$, potentially increasing sputum water content and subsequently mucociliary clearance (MCC).$^{78}$ Exercise may also increase respiratory flow, promoting the cephalad movement of respiratory secretions. Substituting exercise for traditional ACTs may reduce the treatment burden in CF, with recent data suggesting up to $96 \%$ of people of CF already exercise and $48 \%$ may omit their traditional ACT if they have exercised. ${ }^{9}$ Determining the suitability of using exercise as a substitute for traditional ACTs has been identified as one of the top 10 research priorities in $\mathrm{CF}^{10}$ To date, no literature review has specifically reviewed the effectiveness of using exercise as a substitute for traditional ACTs. ${ }^{11} 12$ Therefore, the aim of this review is to examine the evidence for using exercise as a substitute for traditional ACTs in people with CF. 


\begin{tabular}{ll}
\hline Table 1 & Search strategy \\
\hline$\#$ & Searches \\
\hline 1 & cystic fibrosis \\
\hline 2 & $\begin{array}{l}\text { exercise therapy OR physical exertion OR exercis* OR walk* OR jog* OR } \\
\text { run* OR bicycl* OR cycl* }\end{array}$ \\
3 & $\begin{array}{l}\text { physical therapy modalities OR mucociliary clearance OR mucus OR sputum } \\
\text { OR respiratory therapy OR chest physical therapy OR physiotherapy OR } \\
\text { airway clearance OR active cycle of breathing technique OR ACBT OR } \\
\text { autogenic drainage OR AD OR positive expiratory pressure OR PEP OR } \\
\text { oscillating PEP OR OPEP OR flutter OR acapella OR percussion OR vibration } \\
\text { OR drainage, postural OR intrapulmonary percussive ventilation OR IPV } \\
\text { OR chest wall oscillation OR HFCWO OR bottle PEP OR bubble PEP OR } \\
\text { underwater PEP OR UPEP OR rest }\end{array}$ \\
\hline 4 & 1 AND 2 AND 3 \\
\hline
\end{tabular}

\section{METHODS}

We performed a systematic review of the scientific literature investigating the role of exercise as a substitute for traditional ACTs in people with CF. The review was prospectively registered on PROSPERO (available from: https://www.crd.york.ac. uk) and undertaken in accordance with the Preferred Reporting Items for Systematic Reviews and Meta-Analyses guidelines. ${ }^{13}$

\section{Search strategy}

The following electronic databases were searched from the earliest available time until May 2020: MEDLINE, Pubmed, Cochrane (CENTRAL) and CINAHL. Table 1 summarises the search strategy. Reference lists of included studies were screened to identify potentially relevant studies not identified through the database search.

\section{Inclusion and exclusion criteria}

Studies recruiting participants with a diagnosis of CF were included if they compared (1) exercise to rest, in order to evaluate the effects of exercise alone or (2) to a traditional ACT (eg, PD, P\&V, ACBT, AD, PEP, oscillating PEP), in order to directly compare the two treatment strategies.

Exercise was defined as the purposeful movement of the upper or lower limbs or both. Exercise interventions could include periodic huffing and coughing to clear secretions. Studies where exercise solely involved breathing techniques (eg, breathing control, thoracic expansion exercises) were excluded. Randomised controlled trials (RCTs) or quasi-RCTs, either parallel or crossover in design, were eligible. Studies published in English, of any duration and disease phase (eg, stable, unstable), were included. Full-text studies and those published in abstract form only were included.

The outcomes of primary interest were respiratory function tests (eg, forced expiratory volume in one second $\left(\mathrm{FEV}_{1}\right)$, forced vital capacity (FVC), forced expiratory flow at $25-75 \%$ of forced vital capacity $\left(\mathrm{FEF}_{25-75}\right)$, lung clearance index (LCI)), acute respiratory exacerbations (defined by symptoms or initiation of antibiotics based on medical practitioner assessment) and health-related quality of life (HRQOL) measured by generic or disease-specific questionnaires. Secondary outcomes of interest were MCC (assessed by radioaerosol clearance or mucus transport rate), ventilation scans (radiological or nuclear medicine), expectorated sputum weight or volume (wet or dry), perceived ease of expectoration, participant preference and adverse events.

\section{Study selection and data extraction}

After removal of duplicates, two reviewers (NW and SM) independently identified potentially eligible studies by evaluating the title and abstract against the inclusion and exclusion criteria. Full texts of potentially eligible reports were reviewed and a final decision was made regarding eligibility. Where both reviewers could not agree, a third reviewer (KS) assisted in achieving consensus.

Two reviewers (NW and SM) independently evaluated each included study for methodological quality. Data were extracted using a standardised data extraction table, with the reviewers blinded to the other's extracted data. Study design, technique descriptions, participant characteristics and outcome data were recorded. No attempt was made to contact the authors of studies where insufficient detail was provided in the report as most of the studies where data were missing were published more than 20 years previously.

\section{Risk of bias assessment}

Risk of bias was independently determined by two reviewers (NW and SM) according to the Risk of Bias Assessment Tool included in the Cochrane Handbook for Systematic Reviews of Interventions. ${ }^{14}$ Where there was disagreement, a third reviewer (KS) undertook the assessment and, if required, the three reviewers discussed the assessment to achieve consensus.

\section{Data analysis}

Data for exercise versus the two comparators (rest or traditional ACT) were analysed separately. Given the potentially differing physiological effects of the various exercise modalities available (eg, running, cycling, resistance training) and ACTs (eg, ACBT, PEP), data from studies using different exercise modalities or ACTs were not combined for meta-analysis. When multiple RCTs comparing the same exercise regimen and ACT were available, and the studies homogeneous, meta-analyses were conducted using a fixed-effect model, with results reported as mean difference (MD) between groups (95\% CI). If substantial heterogeneity was identified, a random-effect model was used. Heterogeneity was defined as low if $\mathrm{I}^{2}$ was $<25 \%$, moderate if $\mathrm{I}^{2}$ was $25 \%-50 \%$ and substantial if $\mathrm{I}^{2}$ was $>50 \% .{ }^{14}$ Continuous variables were analysed as mean differences and 95\% CIs. Continuous data from cross-over trials were analysed using a generic inverse-variance method where sufficient data were reported. RevMan software was used for the risk of bias table and all meta-analyses. For each of the primary outcomes, the quality of the body of evidence was rated using GRADE (Grading of Recommendations, Asssessment, Development and Evaluations). ${ }^{15}$

\section{RESULTS}

\section{Flow of studies through the review}

After screening the titles and abstracts of identified reports, 199 full reports were reviewed (figure 1). Of these, 184 reports were excluded. Twelve studies, comprising 15 reports, met the eligibility criteria.

\section{Description of the included studies}

Of the 12 studies identified, only one was an RCT, with the remainder crossover trials. Nine of the 12 studies were conducted when participants were clinically stable, two occurred during inpatient treatment for an acute respiratory exacerbation and one did not specify. 


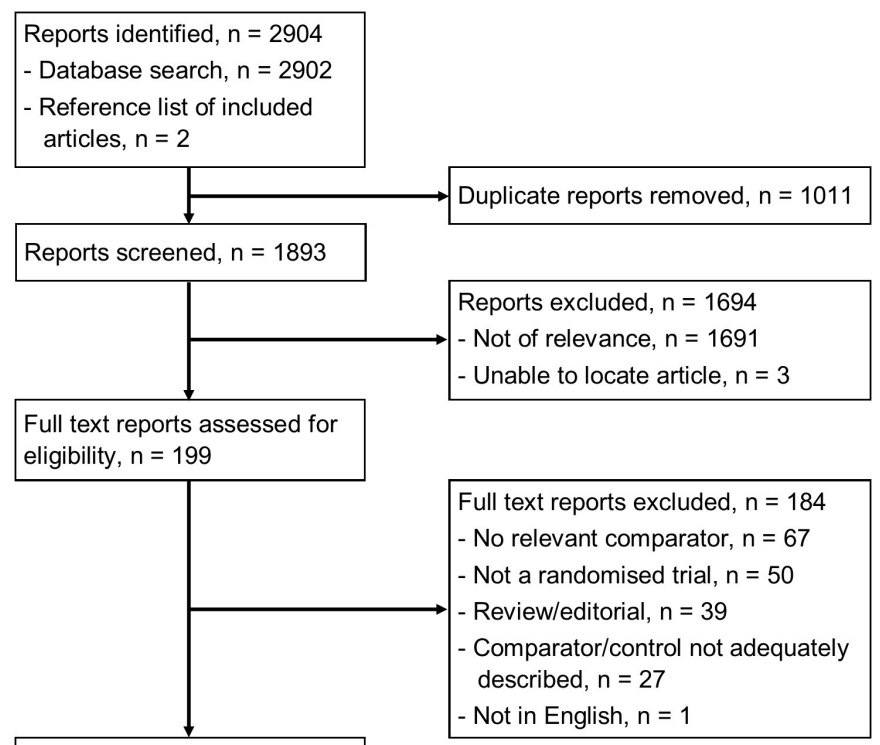

Studies included, $\mathrm{n}=12$

(reports, $\mathrm{n}=15$ )

Figure 1 Flow of studies through the review.

Five studies compared the effects of exercise to rest (table 2). ${ }^{16-20}$ All were crossover in design with small sample sizes $(n=8-24)$ and comprised a single session of each intervention/ comparator. Participants' ages ranged from 15 to 48 years, with percent predicted $\mathrm{FEV}_{1}\left(\mathrm{ppFEV}_{1}\right)$ ranging from $19 \%$ to $113 \%$. Exercise consisted of treadmill $(n=3)$, cycle ergometry $(n=2)$, trampolining $(n=1)$ and mixed exercise $(n=1)$ with durations ranging from 20 to $40 \mathrm{~min}$, with two studies comparing multiple forms of exercise to rest. Prescribed exercise intensities were $60 \%$ of peak oxygen consumption $\left(\mathrm{VO}_{2}\right.$ peak $)(\mathrm{n}=3)$ and heart rate of $140-160 \mathrm{bpm}(\mathrm{n}=1)$, while one study did not report exercise intensity. Rest interventions, of similar duration to the exercise interventions, included sitting quietly, playing billiards or limiting activity without being confined to bed. None of the studies included instructions to use huff, the forced expiratory technique (FET) or cough during exercise or rest. ${ }^{16-20}$ One of the five studies occurred during a period of hospitalisation, however, other differences in study design (eg, differing exercise interventions) meant a comparison based on clinical stability could not be undertaken. ${ }^{16}$

Nine studies (13 reports) were identified that compared exercise to a traditional ACT, ${ }^{18-30}$ with two also comparing exercise to rest. ${ }^{18}{ }^{20}$ Eight studies were of crossover design, with sample sizes ranging from 9 to 32 and comprised a single session of each intervention. The other was an RCT, recruiting 17 participants during a hospital admission (mean length of stay $(\mathrm{SD})=13.0$ (2.6) days). ${ }^{24}$ Participants in the nine studies included children and adults, with $\mathrm{pFEV}_{1}$ ranging from normal to severely impaired. Exercise interventions included cycle ergometry, walking/running on a treadmill, mixed exercise and active video gaming. Target exercise intensities were $60 \% \mathrm{VO}_{2}$ peak $(\mathrm{n}=3)$, $1 / 2 \mathrm{~W} / \mathrm{kg}(\mathrm{n}=1), 80 \%$ maximum working capacity $(\mathrm{n}=1),>40 \%$ heart rate reserve $(n=1)$ or 'submaximal' $(n=1)$ and unclear in two studies. ACT interventions included PEP $(n=4)$, bubble PEP $(n=1)$, oscillating PEP $(n=1)$, ACBT $(n=1)$, a modified form of ACBT $(n=1)$, PD with P\&V $(n=1)$ and PD with thoracic expansion exercises $(n=1)$. Treatment durations were inconsistently reported, ranging from 4 sets of 15 breaths to a total duration of 20 to $40 \mathrm{~min}$. Three studies did not mention whether huffing/
FET or cough was incorporated into either intervention, ${ }^{21} 2224$ four studies used huffing/FET as part of ACT but not the exercise intervention, ${ }^{18} 202325$ while two studies incorporated huffing/ FET with both interventions. ${ }^{26} 27$ Only one of the nine studies occurred during a respiratory exacerbation, with the rest occurring during a stable phase, with other differences in study design (eg, differing exercise/ACT interventions) precluding a comparison of results based on clinical stability. ${ }^{24}$

Figure 2 presents the risk of bias assessment for all 12 studies. Insufficient details regarding study methodology meant it was not possible to classify risk of bias for random sequence generation, allocation concealment and blinding of outcome assessment for majority of the studies.

\section{Exercise versus rest}

\section{Primary outcomes}

Two studies ( $n=20$ participants) reported on the effect of exercise (cycle ergometer and trampolining, mixed exercise) compared with a period of rest on spirometry (figure 3A,B). ${ }^{16} 19$ The intervention duration differed between studies ( $30 \mathrm{~min}$ vs $60 \mathrm{~min}$ ) and neither study reported if huffing/FET was used in either group. There was no significant effect on FVC or FEV $\mathrm{F}_{1}$ in either study. The mean changes in $\mathrm{FEV}_{1}$ with exercise ranged from -0.05 $\mathrm{L}$ to $0.01 \mathrm{~L}$ and from $-0.02 \mathrm{~L}$ to $-0.01 \mathrm{~L}$ for rest. ${ }^{16}{ }^{19}$ Metaanalysis was not possible due to the different types of exercise investigated. The quality of the evidence (GRADE) was assessed as being low for both $\mathrm{FVC}$ and $\mathrm{FEV}_{1}$ due to unclear blinding and imprecision.

Peak expiratory flow (PEF) rates and peak expiratory to peak inspiratory flow ratios (PEF:PIF) were reported by two studies undertaken by the same research group (figure $3 \mathrm{C}, \mathrm{D}) .{ }^{17} 18$ Treadmill exercise resulted in a significantly higher PEF than rest in both studies, with mean differences ranging from 1.00 to 1.16L/s. The PEF:PIF was higher with treadmill compared with rest (MD 0.05 to 0.12 ), demonstrating a PEF bias. Compared with rest, one study found cycle ergometry improved PEF (MD 1.19 (0.96 to 1.42$) \mathrm{L} / \mathrm{s}$ ) and PEF:PIF (MD 0.13 (0.04 to 0.21$)) .^{17}$ The quality of the evidence (GRADE) for PEF and PEF:PIF was assessed as being moderate due to indirectness.

No studies comparing exercise and rest reported on respiratory exacerbations or HRQOL.

\section{Secondary outcomes}

Treadmill exercise resulted in significantly greater mucus clearance from the whole lung immediately after the 20 min intervention period (mean difference (95\% CI 2.6 (1.6 to 3.6)\%, 1 study, 15 participants). ${ }^{20}$ When analysed by lung region, treadmill exercise also resulted in significantly greater mucus clearance from the intermediate and peripheral regions but not the central region. These differences were maintained over $60 \mathrm{~min}$ postintervention except for the central region, where rest resulted in greater mucus clearance during this period. ${ }^{20}$

No studies reported on the relative effects of exercise compared with rest on ventilation scans.

Sputum weight was reported in two studies $(n=20$ participants). ${ }^{1619}$ One study ( $\mathrm{n}=8$ participants) found a trend towards mixed exercise (including walking, cycling, step ups, star jumps) producing a greater sputum weight than rest (MD $4.4(-0.07$ to 8.8$) \mathrm{g}){ }^{16}$ In the other study ( $\mathrm{n}=12$ participants), trampoline exercise resulted in more sputum being expectorated $(7.60$ (SD 4.5)g) than the control period (billiards) (3.8 (SD 2.2)g) $(p=0.021) .{ }^{19}$ There was also a trend for cycling to result in more sputum being expectorated $(6.0$ (SD 3.9)g) compared with a 
Table 2 Summary of included studies

\begin{tabular}{|c|c|c|c|c|c|c|c|c|c|c|c|}
\hline \multirow[b]{2}{*}{ Reference } & \multirow{2}{*}{$\begin{array}{l}\text { Study } \\
\text { design }\end{array}$} & \multirow[b]{2}{*}{ Exercise } & \multirow[b]{2}{*}{ Comparator } & \multicolumn{2}{|c|}{ Sample size } & \multicolumn{2}{|c|}{ Age (years)* } & \multicolumn{2}{|l|}{$\operatorname{ppFEV}_{1}{ }^{*}$} & \multirow{2}{*}{$\begin{array}{l}\text { Clinical } \\
\text { stability }\end{array}$} & \multirow[b]{2}{*}{ Relevant outcomes } \\
\hline & & & & Ex & Com & Ex & Com & Ex & Com & & \\
\hline \multicolumn{12}{|l|}{ Exercise versus rest } \\
\hline Baldwin et al ${ }^{16}$ & Crossover & Mixed & Rest & 8 & & $18-27$ & & \multicolumn{2}{|l|}{$63.6(6.6) \dagger$} & $\begin{array}{l}\text { Acute } \\
\text { exacerbation }\end{array}$ & $\begin{array}{l}\text { Respiratory function } \\
\text { tests, sputum weight }\end{array}$ \\
\hline Dwyer et all ${ }^{17}$ & Crossover & $\begin{array}{l}\text { Cycle ergometry } \\
\text { treadmill }\end{array}$ & Rest & 14 & & $\begin{array}{l}18-44 \\
27(7) \ddagger\end{array}$ & & \multicolumn{2}{|l|}{$\begin{array}{l}19-108, \\
55(27) \ddagger\end{array}$} & Stable & $\begin{array}{l}\text { Respiratory function } \\
\text { tests, participant ease } \\
\text { of expectoration }\end{array}$ \\
\hline $\begin{array}{l}\text { Kreimler et al } \\
(\text { Radkte et al) })^{19}\end{array}$ & Crossover & $\begin{array}{l}\text { Cycle ergometry } \\
\text { trampoline }\end{array}$ & Rest (billiards) & 12 & & $\begin{array}{l}15.9-28.9 \\
20.8(3.5) \ddagger\end{array}$ & & \multicolumn{2}{|c|}{$\begin{array}{l}33.3-89.9 \\
62.8(17.7) \ddagger\end{array}$} & Not specified & $\begin{array}{l}\text { Respiratory function } \\
\text { tests, sputum weight }\end{array}$ \\
\hline \multicolumn{12}{|c|}{ Exercise versus rest/traditional ACT } \\
\hline Dwyer et a $\left.\right|^{18}$ & Crossover & Treadmill & $\begin{array}{l}\text { Rest } \\
\text { Flutter }\end{array}$ & 24 & & $\begin{array}{l}19-48 \\
30(8) \ddagger\end{array}$ & & \multicolumn{2}{|l|}{$\begin{array}{l}28-86 \\
51(18) \ddagger\end{array}$} & Stable & $\begin{array}{l}\text { Respiratory function } \\
\text { tests, participant ease } \\
\text { of expectoration, } \\
\text { adverse events }\end{array}$ \\
\hline Dwyer et al $l^{20}$ & Crossover & Treadmill & $\begin{array}{l}\text { Rest } \\
\text { PEP }\end{array}$ & 15 & & $\begin{array}{l}18-48 \\
27(9) \ddagger\end{array}$ & & \multicolumn{2}{|l|}{$\begin{array}{l}31-113 \\
65(23) \ddagger\end{array}$} & Stable & $\begin{array}{l}\text { Mucociliary } \\
\text { clearance, adverse } \\
\text { events }\end{array}$ \\
\hline \multicolumn{12}{|c|}{ Exercise versus traditional ACT } \\
\hline Aquino et a $\left.\right|^{21}$ & Crossover & $\begin{array}{l}\text { Active video } \\
\text { game }\end{array}$ & PEP & 13 & & $7-29$ & & \multicolumn{2}{|l|}{$46-102$} & Stable & Sputum weight \\
\hline Balestri et $a l^{22}$ & Crossover & Cycle ergometry & Bubble PEP & 13 & & $10-41$ & & \multicolumn{2}{|l|}{$54-95$} & Stable & Sputum weight \\
\hline $\begin{array}{l}\text { Bilton et al } \\
\left(\text { Bilton et al) }{ }^{23}\right.\end{array}$ & Crossover & Cycle ergometry & ACBT with PD & 18 & & $16-34$ & & \multicolumn{2}{|l|}{$18-98$} & Stable & $\begin{array}{l}\text { Respiratory function } \\
\text { tests, sputum } \\
\text { weight, participant } \\
\text { perception and } \\
\text { treatment preference, } \\
\text { adverse events }\end{array}$ \\
\hline Cerny $^{24}$ & RCT & Cycle ergometry & PD with P\&V & 9 & 8 & $15.4(4.9) \ddagger$ & $15.9(4.9) \ddagger$ & NS & NS & $\begin{array}{l}\text { Acute } \\
\text { exacerbation }\end{array}$ & $\begin{array}{l}\text { Respiratory function } \\
\text { tests, sputum weight }\end{array}$ \\
\hline $\begin{array}{l}\text { Falk et al } \\
1988^{25}\end{array}$ & Crossover & Cycle ergometry & PEP & 12 & & NS & & \multicolumn{2}{|l|}{ NS } & Stable & $\begin{array}{l}\text { Respiratory function } \\
\text { tests, sputum weight }\end{array}$ \\
\hline $\begin{array}{l}\text { Lannefors et al } \\
1992^{26}\end{array}$ & Crossover & Cycle ergometry & $\begin{array}{l}\text { PEP } \\
\text { PD with TEE }\end{array}$ & 9 & & $12-36$ & & \multicolumn{2}{|l|}{$\begin{array}{l}20-78 \\
51 \text { (NS) } \ddagger\end{array}$} & Stable & Mucociliary clearance \\
\hline $\begin{array}{l}\text { Reix et al } 2012 \\
\text { (Reix et al } \\
2009)^{27}\end{array}$ & Crossover & Mixed & mACBT & 32 & & $12(3) \ddagger$ & & $93(14) \S$ & $94(14) \S$ & Stable & $\begin{array}{l}\text { Respiratory function } \\
\text { tests, sputum } \\
\text { weight, participant } \\
\text { satisfaction, adverse } \\
\text { events }\end{array}$ \\
\hline
\end{tabular}

${ }^{*}$ Range unless otherwise specified.

tMean (SEM).

$\ddagger$ Mean (SD).

§Mean $(95 \% \mathrm{Cl})$.

$A C B T$ with $P D$, active cycle of breathing technique with postural drainage; $A C T$, airway clearance technique; $C P E T$, cardiopulmonary exercise testing; mACBT, modified active cycle of breathing technique; NS, not specified; PD with P\&V, postural drainage, percussion and vibration; PD with TEE, postural drainage and thoracic expansion exercises; PEP, positive expiratory pressure; $\mathrm{ppFEV}_{1}$, percent predicted forced expiratory volume in one second.

control period $(p=0.074) .{ }^{19}$ Given the different types of exercise used in these two studies, meta-analysis was not possible.

Two studies ( $\mathrm{n}=38$ participants) compared exercise and rest on participant-reported ease of expectoration, measured via a $10 \mathrm{~cm}$ visual analogue scale. ${ }^{17}{ }^{18}$ Immediately after treadmill exercise, neither study found a significant difference in ease of expectoration (figure 4A). After a $20 \mathrm{~min}$ recovery period, however, there was improvement in ease of expectoration with treadmill exercise compared with rest in one study (figure 4B). Similarly, the study ( $\mathrm{n}=14$ participants) comparing cycle ergometer exercise to rest found no significant difference in ease of expectoration immediately postexercise, however, there was a significant improvement in ease of expectoration after a subsequent $20 \mathrm{~min}$ rest period in favour of exercise (MD 2.0 (0.2 to 3.8$) \mathrm{cm}$ ) (figure $4 \mathrm{~A}, \mathrm{~B}){ }^{17}$

No studies reported participant preference for exercise versus rest. Two studies ( $n=39$ participants) measured adverse events, with both finding no adverse events in either the exercise (treadmill) or rest groups. ${ }^{18} 20$

\section{Exercise versus ACT}

Primary outcomes

Five studies were identified that reported on the effect of exercise compared with traditional ACTs on respiratory function (figure 5). ${ }^{1823-2527}$ Due to differences in exercise and traditional ACT regimens and limited published data provided in some 


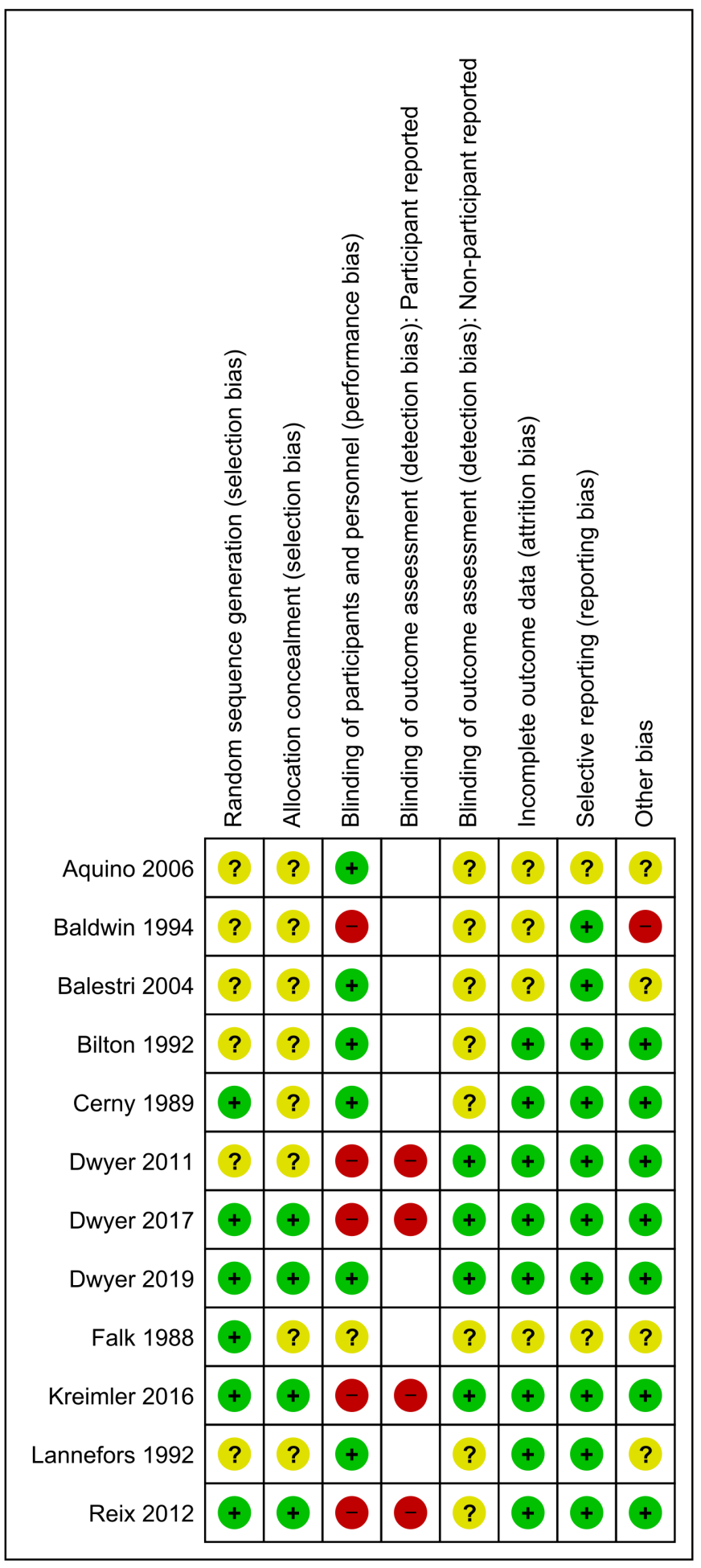

Figure 2 Risk of bias assessment for the 12 included studies. +=low; -=high; ?=unclear.

study reports, meta-analyses were not possible. One study ( $\mathrm{n}=12$ participants) noted that cycle ergometry resulted in an increase in LCI, which was not seen with PEP but did not provide data. ${ }^{25}$ These authors also reported no significant difference between cycle ergometry and PEP for FVC, $\mathrm{FEV}_{1}$, functional residual capacity (FRC), total lung capacity (TLC), maximum expiratory flow at $25 \%$ of vital capacity $\left(\mathrm{MEF}_{25}\right)$, maximum expiratory flow at $50 \%$ of vital capacity $\left(\mathrm{MEF}_{50}\right)$ and residual volume (RV without providing data. Another study ( $\mathrm{n}=18$ participants) comparing cycle ergometry to ACBT reported that exercise resulted in an immediate increase in $\mathrm{FEV}_{1}$ postexercise $(\mathrm{p}<0.05)$, with no change in $\mathrm{FVC}$ or $\mathrm{FEV}_{1}$ for either intervention at $30 \mathrm{~min}$ post-treatment but did not provide the data. ${ }^{23}$ In another study $\left(n=32\right.$ participants), mixed exercise improved $\mathrm{ppFEV}_{1}$ compared with modified ACBT (MD 3 (0 to 6)\%) when measured after a 40 min recovery period. ${ }^{27}$ Both the exercise and traditional ACT groups performed the FET. The only study ( $\mathrm{n}=17$ participants) to compare exercise (cycle ergometry) to a traditional ACT (PD with P\&V) for longer than a single session of each intervention (a 2-week hospitalisation period) found no significant difference between interventions for the mean change in percent predicted FVC (14.6\% vs $22.4 \%)$, FEV $_{1}$ (11.3\% vs $\left.18.4 \%\right), \mathrm{FEF}_{25-75}(4.1 \%$ vs $9.6 \%)$ or FRC $(-19.4 \%$ vs $-10.1 \%) .{ }^{24}$ The quality of the evidence (GRADE) for FVC and $\mathrm{FEF}_{25-75}$ was both assessed as being very low due to imprecision and unclear blinding and allocation concealment. The quality of the evidence (GRADE) for $\mathrm{FEV}_{1}$ was assessed as being low due to unclear blinding and imprecision.

PEF and PEF:PIF bias were compared between treadmill exercise and the Flutter in one study ( $n=24$ participants). ${ }^{18}$ No significant difference between treadmill and Flutter was found for PEF (figure 5D). While not included in the original study report, a paired samples t-test of the raw data provided in a supplement by the study authors for PEF:PIF revealed a significant difference in favour of the Flutter (figure $5 \mathrm{E}$ ). ${ }^{18}$ The quality of the evidence (GRADE) for both PEF and PEF:PIF was assessed as being moderate due to indirectness.

No studies comparing exercise and ACT reported HRQOL or respiratory exacerbation rates.

\section{Secondary outcomes}

Two studies ( $n=24$ participants) investigated the effect of exercise compared with traditional ACTs on MCC. ${ }^{20} 26$ There was a trend towards lower MCC following cycle ergometry, when compared with PEP and PD with thoracic expansion exercises, but this did not reach statistical significance ( $\mathrm{n}=9$ participants). ${ }^{26}$ The FET was included with both the exercise and traditional ACT interventions. In another study ( $n=15$ participants) that compared treadmill exercise to PEP, treadmill exercise resulted in significantly less overall MCC. ${ }^{20}$ Mucus clearance from the peripheral and intermediate regions was similar between interventions, with the central region displaying greater clearance with PEP compared with treadmill. Importantly, the PEP intervention included the use of FET, while the treadmill intervention did not. ${ }^{20}$

No studies reported on the relative effects of exercise compared with traditional ACTs on ventilation scans.

Sputum weight was measured in six studies. ${ }^{21-2527}$ Four studies ( $n=75$ participants) reported no significant difference between exercise and traditional ACT. ${ }^{2122} 2427$ One of these studies $(\mathrm{n}=32$ participants) however did report a non-significant trend favouring more sputum being produced with exercise (MD 0.6 $(-0.2$ to 1.4$) \mathrm{g}$ ), with this study being the only study to include huffing/FET during the exercise intervention. ${ }^{27}$ Two studies ( $n=30$ participants) found that exercise produced significantly less sputum during the intervention period compared with traditional ACT. ${ }^{23} 25$ Both of these studies included FET in the ACT intervention but not the exercise intervention. These two studies reported no significant difference in the weight of sputum expectorated during the postintervention follow-up period $(15 \mathrm{~min}$ in one study and 23 hours in the other). 


\section{A) FVC}

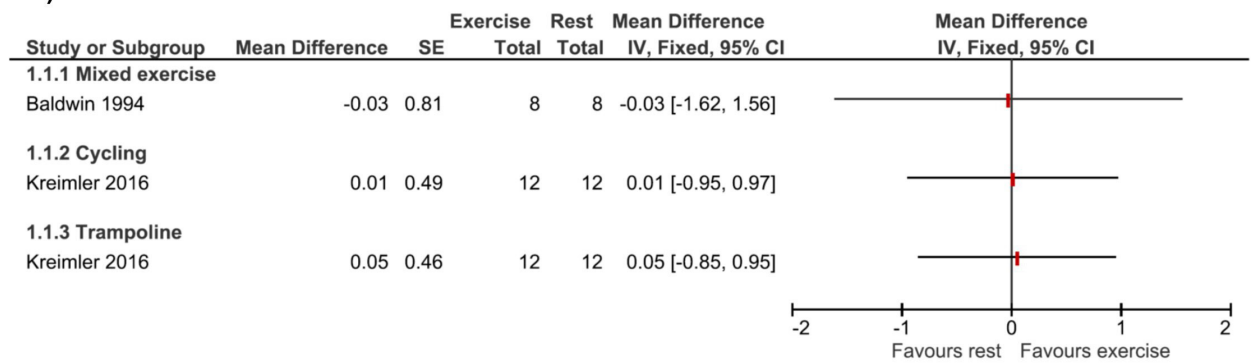

B) $\mathrm{FEV}_{1}$

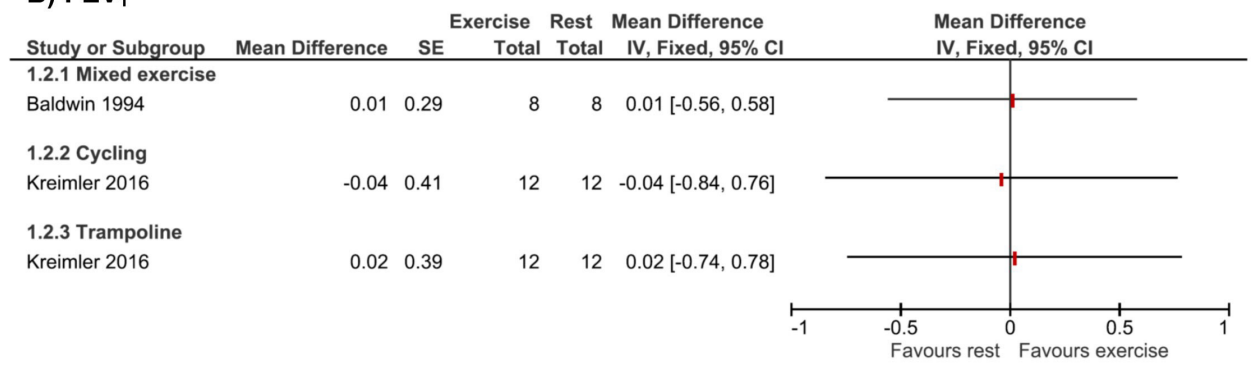

C) PEF

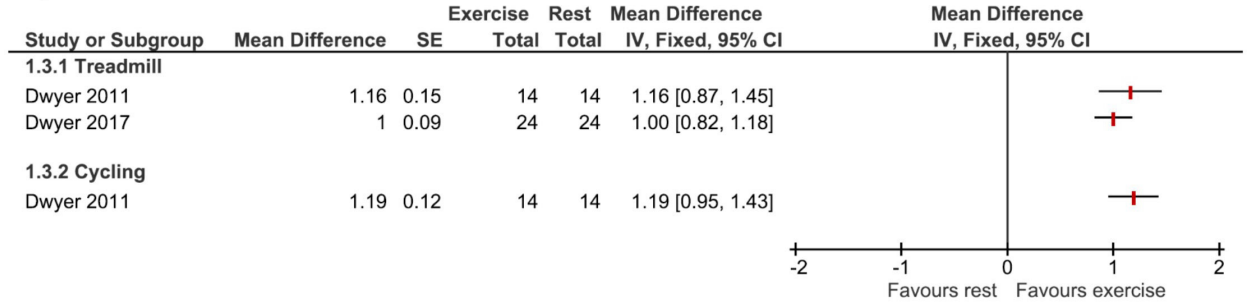

D) PEF:PIF

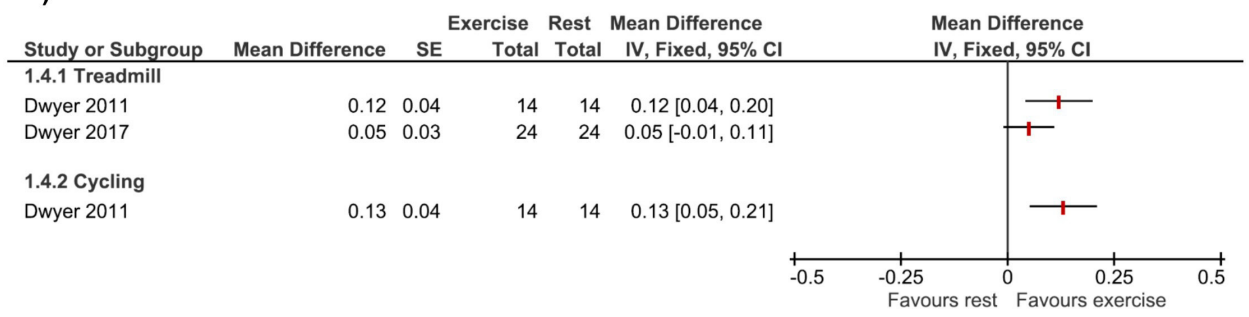

Figure 3 Exercise versus rest-pulmonary function tests. $\mathrm{FEV}_{1}$, forced expiratory volume in one second (L); FVC, forced vital capacity (L); PEF, peak expiratory flow (L/sec); PEF:PIF, peak expiratory flow to peak inspiratory flow ratio.

There was no significant difference in change in ease of expectoration between treadmill and Flutter, either during the intervention or recovery (one study, $n=24$ participants). ${ }^{18}$ Patient preference was reported in one study $(n=18$ participants) however the design and reporting method means a direct comparison of exercise to traditional ACT could not be made. ${ }^{23}$

Adverse events were reported by four studies ( $n=89$ participants). ${ }^{18} \quad 202327$ Two studies ( $\quad 2=39$ participants), which compared treadmill to either Flutter or PEP, reported no adverse events. ${ }^{1820}$ No adverse effects on heart rate or oxygen saturation during exercise were reported in another study $(n=18$ participants) however the authors did not comment on any adverse events in the ACT group (ACBT with PD). ${ }^{23}$ One study $(n=32$ participants) reported four adverse events in the exercise group (mixed exercise) compared with one in the traditional ACT group (modified ACBT) however this did not reach statistical significance (relative risk $(95 \% \mathrm{CI}) 4.00(0.47$ to 33.86$)) .{ }^{27}$ The adverse events reported were fatigue, breathlessness and oxygen desaturation $\left(\mathrm{SpO}_{2}<92 \%\right)$, which resolved rapidly with interruption of the intervention. ${ }^{27}$ The authors did not specify which events occurred with each intervention.

\section{DISCUSSION}

The aim of this systematic review was to examine the evidence for exercise as a substitute for traditional ACTs in people with CF. The review identified 12 studies comparing exercise to either rest or traditional ACTs. The studies were of short duration and heterogeneous in design. When compared with rest, exercise increased PEF, improved MCC and increased the ease of expectoration. The evidence comparing exercise to traditional ACTs was mixed, which may reflect variability in the use of huffing/ FET during the exercise routine.

Compared with rest, both cycling and treadmill exercise significantly increased PEF, with the PEF being in excess of the $30-60 \mathrm{~L} / \mathrm{min}$ that is proposed as the minimum expiratory flow required for cephalad secretion movement. ${ }^{17} 1831$ While these findings support the physiological rationale for exercise 
A Immediately post exercise

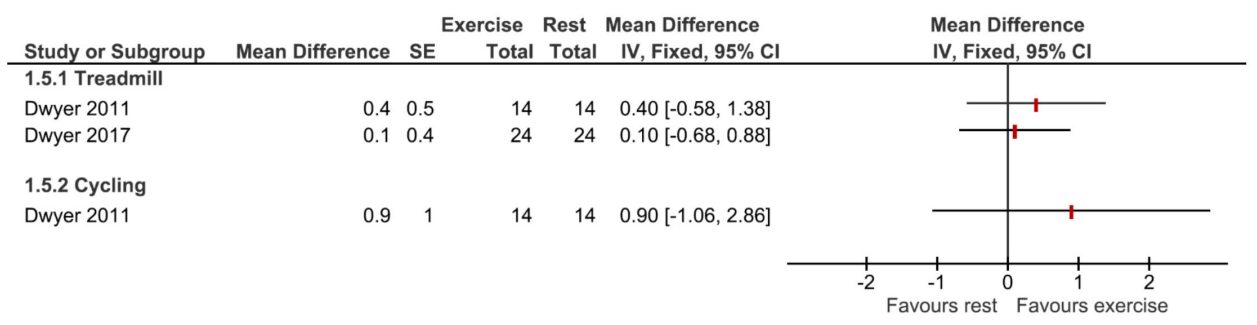

B Post recovery

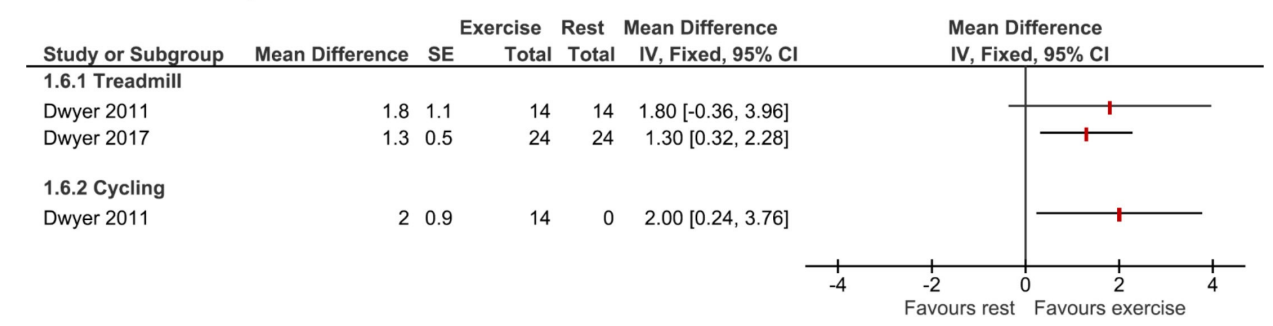

Figure 4 Exercise versus rest-ease of expectoration. Mean difference in $\mathrm{cm}$ measured on a visual analogue scale.

as a potential ACT substitute, the PEF:PIF for both treadmill exercise and cycling did not exceed the proposed PEF bias of $>1.1$. The implications of not achieving this bias are unclear as not all traditional ACTs achieve this. ${ }^{31}$ Meta-analysis also found that ease of expectoration was improved by treadmill exercise when compared with rest. Interestingly, this improvement was

\section{A FVC}

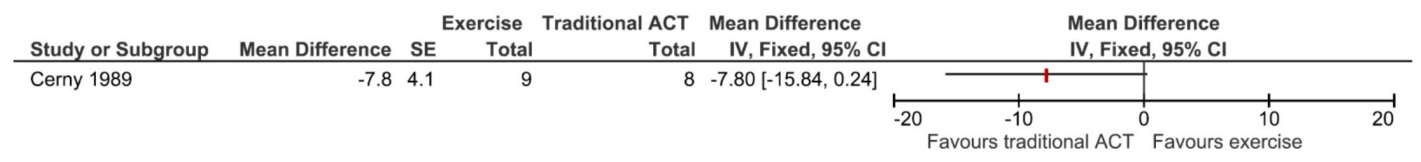

\section{B FEV $_{1}$}

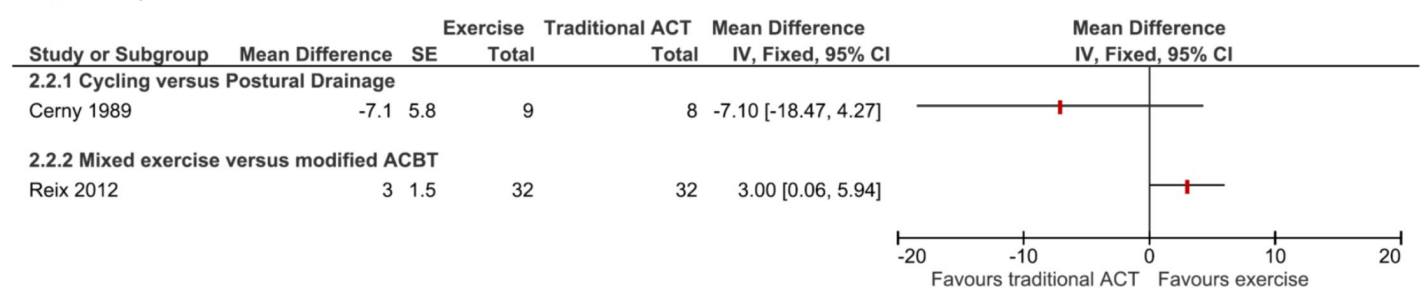

\section{FEF $_{25-75}$}

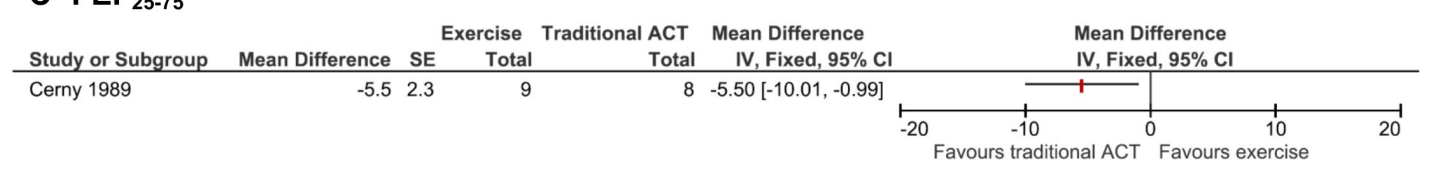

\section{PEF}

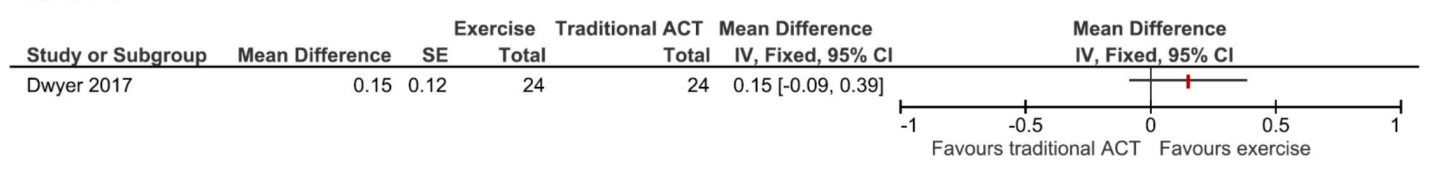

\section{E PEF:PIF}

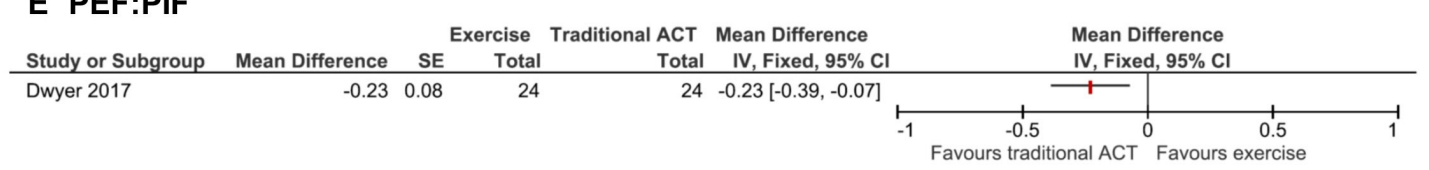

Figure 5 Exercise versus traditional airway clearance technique-pulmonary function tests. ACBT, active cycle of breathing technique; ACT, airway clearance technique; $\mathrm{FEF}_{25-75}$, forced expiratory flow between $25 \%$ and $75 \%$ of FVC (percent predicted); FEV ${ }_{1}$, forced expiratory volume in one second (percent predicted); FVC, forced vital capacity (percent predicted); PEF, peak expiratory flow (L/sec); PEF:PIF, peak expiratory flow to peak inspiratory flow ratio. 
not evident immediately postintervention but occurred after a $20 \mathrm{~min}$ recovery period. The single study comparing ease of expectoration between cycle ergometry and rest also found an improvement in ease of expectoration 20 min after exercise but not immediately after. ${ }^{17}$ The differences in ease of expectoration that were documented (mean differences $\geq 1.4 \mathrm{~cm}$ ) may be clinically meaningful. While the cause of the delayed response in ease of expectoration is unclear, it is potentially an important finding for clinical practice in that patients should be counselled that changes in ease of expectoration associated with exercise may not occur immediately post exercise when judging its effectiveness as a substitute for traditional ACTs.

Based on the results of this review, it is possible that in the short term, exercise may have a similar effect as traditional ACTs on FVC, $\mathrm{FEV}_{1}$ and $\mathrm{FEF}_{25-75}{ }^{23-25} 27$ These findings provide equipoise for exploring the effectiveness of exercise as a substitute for traditional ACTs over the medium to longer term in parallelgroup RCTs. While assessment of respiratory function in such a study would likely include $\mathrm{FEV}_{1}$, there is potentially a role for the use of other outcomes, such as LCI, which may be more sensitive to change. The effect of substituting exercise for traditional ACTs on respiratory exacerbation rates, HRQOL, treatment burden and adherence with the overall treatment regimen needs to be further investigated. The design of future trials comparing exercise with traditional ACTs should consider whether huffing/FET is incorporated as part of the exercise regimen, as this may be a key determinant of outcome. The one study including huffing/ FET in both the exercise and traditional ACT groups found no significant difference between the interventions in sputum weight. ${ }^{27}$ Conversely, the two studies that found in favour of traditional ACTs both incorporated huffing/FET as part of the ACT regimen but not the exercise regimen. ${ }^{23}{ }^{25}$ Findings were similar for MCC. ${ }^{20}{ }^{26}$ It is unclear whether the difference in MCC found in the study favouring traditional ACT over exercise was clinically meaningful as there are no published data indicating a minimal important difference for MCC. ${ }^{20}$ Likewise, it is unclear whether the higher sputum weight achieved with ACBT compared with cycling is of clinical importance given the lack of data for a minimum important difference for sputum weight. ${ }^{23}$ These findings suggest that if exercise is to be used as a substitute for traditional ACTs, huffing/FET should also be included as part of the exercise regimen. ${ }^{31}$ Several, but not all, current clinical guidelines make reference to including huffing/FET when exercise is used to promote secretion clearance, and the evidence from this review would support this being included as a recommendation in future clinical guidelines. ${ }^{12} 3233$

There were several limitations to this review. A lack of detail in some included studies limited the ability to determine the risk of bias. It is possible that publication bias could have affected the conclusions of the review if negative studies were not published, however, the inclusion of studies reported only in abstract form may have mitigated this risk. We were unable to formally assess publication bias using funnel plots due to the small number of included studies for each comparison. The study designs were heterogeneous, with a wide variety of exercise and traditional ACT interventions and studies recruited a mixture of adult and paediatric patients, all of which may affect interpretation of the results. Combined with minimal data provided by some studies, the ability to perform meta-analyses was limited and where undertaken, the results should be interpreted in the context of only two included studies. The majority of studies was of short duration, hence it is not possible to make any conclusions on the medium to long-term effects of exercise versus traditional ACTs. All of the studies had small sample sizes $(n \leq 32)$ and were likely underpowered, so small differences between exercise and ACTs cannot be excluded.

While longer term studies comparing exercise alone to traditional ACTs as a form of airway clearance are required, there are unique considerations that will need to be accommodated in the clinical trial design. First, exercise is likely to have multiple benefits for people with CF beyond just improving airway clearance. Exercise improves aerobic capacity and higher aerobic capacity has been linked to improve survival in CF. ${ }^{42}$ Exercise is therefore likely to remain a component of the CF treatment regimen into the foreseeable future, even in the age of modulator therapy. There would be ethical concerns around withholding exercise from the ACT group in a true exercise versus traditional ACT study due to the non-respiratory benefits of exercise. ${ }^{34}$ Therefore, it is likely that future studies will take the form of exercise versus ACT and exercise. Second, measuring adherence with both exercise and traditional ACTs will be important in future studies given the often poor adherence with these interventions. Electronic methods of objectively measuring adherence with both exercise/physical activity (eg, activity monitors) and traditional ACTs (eg, in-line devices to measure pressure and flow) are available and should be considered an essential component in any future studies investigating exercise as a substitute for traditional ACTs. ${ }^{35}{ }^{36}$ The results of a feasibility trial investigating such a study design have been recently published and may provide the basis for a larger multicentred trial. ${ }^{37}$

This systematic review found that, based on short-term studies, exercise may have a similar effect to traditional ACTs on respiratory function and may produce a similar weight of expectorated sputum when combined with huffing/FET. It also found that treadmill exercise improves the ease of sputum expectoration compared with rest. Longer duration studies are required to determine whether exercise can be used as a substitute for traditional ACTs in the modern era of CF management.

Contributors Study design: NW, SM, KS, AEH. Data collection: NW, SM. Data analysis: NW, SM, KS, AEH. Draft manuscript: NW. Manuscript review: NW, SM, KS, AEH.

Funding This study was supported by an Australian Government Research Training Programme Scholarship.

Competing interests None declared.

Patient consent for publication Not required.

Provenance and peer review Not commissioned; externally peer reviewed.

Data availability statement No data are available.

\section{REFERENCES}

1 Button BM, Wilson C, Dentice R, et al. Physiotherapy for cystic fibrosis in Australia and New Zealand: a clinical practice guideline. Respirology 2016;21:656-67.

2 Daniels T, Morrison L, Harnett N, et al. Standards of care and good clinical practice for the physiotherapy management of cystic fibrosis. 3rd edn, 2017. https://www. cysticfibrosis.org.uk/the-work-we-do/clinical-care/consensus-documents\#

3 Dwyer TJ, Elkins MR, Bye PTP. The role of exercise in maintaining health in cystic fibrosis. Curr Opin Pulm Med 2011;17:1-60.

4 Hebestreit H, Hulzebos EHJ, Schneiderman JE, et al. Cardiopulmonary exercise testing provides additional prognostic information in cystic fibrosis. Am J Respir Crit Care Med 2019;199:987-95.

5 Hoo ZH, Daniels T, Wildman MJ, et al. Airway clearance techniques used by people with cystic fibrosis in the UK. Physiotherapy 2015;101:340-8.

6 Ward N, Stiller K, Holland AE, et al. Exercise is commonly used as a substitute for traditional airway clearance techniques by adults with cystic fibrosis in Australia: a survey. J Physiother 2019;65:43-50.

7 Hebestreit A, Kersting U, Basler B, et al. Exercise inhibits epithelial sodium channels in patients with cystic fibrosis. Am J Respir Crit Care Med 2001;164:443-6.

8 Schmitt L, Wiebel M, Frese F, et al. Exercise reduces airway sodium ion reabsorption in cystic fibrosis but not in exercise asthma. Eur Respir J 2011;37:342-8. 
9 Rowbotham NJ, Smith SJ, Davies G, et al. Can exercise replace airway clearance techniques in cystic fibrosis? A survey of patients and healthcare professionals. J Cyst Fibros 2020;19:e19-24.

10 Rowbotham NJ, Smith S, Leighton PA, et al. The top 10 research priorities in cystic fibrosis developed by a partnership between people with CF and healthcare providers. Thorax 2018;73:388-90.

11 van Doorn N. Exercise programs for children with cystic fibrosis: a systematic review of randomized controlled trials. Disabil Rehabil 2010;32:41-9.

12 Radtke T, Nevitt SJ, Hebestreit H, et al. Physical exercise training for cystic fibrosis. Cochrane Database Syst Rev 2017;11:CD002768.

13 Moher D, Liberati A, Tetzlaff J, et al. Preferred reporting items for systematic reviews and meta-analyses: the PRISMA statement. BMJ 2009;339:b2535.

14 Higgins J, Green S. Cochrane Handbook for systematic reviews of interventions v5.1. The Cochrane Collaboration. Available: www.handbook.cochrane.org [Accessed 2 Mar 2020].

15 Balshem H, Helfand M, Schünemann HJ, et al. Grade guidelines: 3. rating the quality of evidence. J Clin Epidemiol 2011;64:401-6.

16 Baldwin DR, Hill AL, Peckham DG, et al. Effect of addition of exercise to chest physiotherapy on sputum expectoration and lung function in adults with cystic fibrosis. Respir Med 1994;88:49-53.

17 Dwyer TJ, Alison JA, McKeough ZJ, et al. Effects of exercise on respiratory flow and sputum properties in patients with cystic fibrosis. Chest 2011;139:870-7.

18 Dwyer TJ, Zainuldin R, Daviskas E, et al. Effects of treadmill exercise versus Flutter@ on respiratory flow and sputum properties in adults with cystic fibrosis: a randomised controlled, cross-over trial. BMC Pulm Med 2017;17:14.

19 Kriemler S, Radtke T, Christen G, et al. Short-term effect of different physical exercises and physiotherapy combinations on sputum expectoration, oxygen saturation, and lung function in young patients with cystic fibrosis. Lung 2016;194:659-64.

20 Dwyer TJ, Daviskas E, Zainuldin R, et al. Effects of exercise and airway clearance (positive expiratory pressure) on mucus clearance in cystic fibrosis: a randomised crossover trial. Eur Respir J 2019;53:1801793.

21 Aquino A, Balestri E, Dall'Ara S, et al. 374 efficacy of physical exercise playing a video game for mucus clearance in patients with cystic fibrosis. J Cyst Fibros 2006;5:S83.

22 Balestri E, Ambroni M, Dall'Ara S, et al. Efficacy of physical exercise for mucus clearance in patients with cystic fibrosis (CF). Pediatr Pulmonol 2004;38:316.
23 Bilton D, Dodd ME, Abbot JV, et al. The benefits of exercise combined with physiotherapy in the treatment of adults with cystic fibrosis. Respir Med 1992;86:507-11.

24 Cerny FJ. Relative effects of bronchial drainage and exercise for in-hospital care of patients with cystic fibrosis. Phys Ther 1989;69:633-9.

25 Falk M, Kelstrup M, Andersen J. PEP treatment or physical exercise - effects on secretions expectorated and indices of central and peripheral airway function. 10th International Cystic Fibrosis Congress; 5-10 March, Sydney, Australia, 1988:35.

26 Lannefors L, Wollmer P. Mucus clearance with three chest physiotherapy regimes in cystic fibrosis: a comparison between postural drainage, PEP and physical exercise. Eur Respir J 1992;5:748-53.

27 Reix P, Aubert F, Werck-Gallois M-C, et al. Exercise with incorporated expiratory manoeuvres was as effective as breathing techniques for airway clearance in children with cystic fibrosis: a randomised crossover trial. J Physiother 2012;58:241-7.

28 Bilton D, Dodd M, Webb A. The benefits of exercise combined with physiotherapy in cystic fibrosis. Pediatr Pulmonol 1990;9.

29 Radtke T, Christen G, Huber MK, et al. WS14.2 short-term effect of different physical exercise-physiotherapy combinations on sputum production, oxygen saturation and lung function in young patients with cystic fibrosis. J Cyst Fibros 2015;14:S27.

30 Reix P, Aubert F, Kassai B, et al. Better satisfaction of cystic fibrosis paediatric patients with autogenic drainage associated to exercise compared to conventional chest physiotherapy. J Cyst Fibros 2009;8:S73.

31 Mcllwaine M, Bradley J, Elborn JS, et al. Personalising airway clearance in chronic lung disease. Eur Respir Rev 2017;26:160086.

32 Castellani C, Duff AJA, Bell SC, et al. ECFS best practice guidelines: the 2018 revision. J Cyst Fibros 2018;17:153-78.

33 International Physiotherapy Group for Cystic Fibrosis. Physiotherapy for people with cystic fibrosis: from infant to adult, 2018. Available: www.ecfs.eu/ipg_cf/booklet

34 Ward N, Stiller K, Holland AE. Exercise as a therapeutic intervention for people with cystic fibrosis. Expert Rev Respir Med 2019;13:449-58.

35 Bradley J, O'Neill B, Kent L, et al. Physical activity assessment in cystic fibrosis: a position statement. J Cyst Fibros 2015;14:e25-32.

36 Ward N, Ward B, Stiller K, et al. Positive expiratory pressure therapy recorder for assessing compliance: a new device for clinical practice and research. Pediatr Pulmonol 2018;53:S341-2.

37 Ward N, Stiller $\mathrm{K}$, Rowe $\mathrm{H}$, et al. Airway clearance by exercising in mild cystic fibrosis (ACE-CF): a feasibility study. Respir Med 2018;142:23-8. 